Article

\title{
Using Deliberative Democracy for Better Urban Decision-Making through Integrative Thinking
}

\author{
Janette Hartz-Karp and Dora Marinova *(D) \\ Curtin University Sustainability Policy (CUSP) Institute, Curtin University, Perth, WA 6845, Australia; \\ J.Hartz-Karp@curtin.edu.au \\ * Correspondence: D.Marinova@curtin.edu.au
}

check for updates

Citation: Hartz-Karp, J.; Marinova, D. Using Deliberative Democracy for Better Urban Decision-Making through Integrative Thinking. Urban Sci. 2021, 5, 3. https://dx.doi.org/ $10.3390 /$ urbansci5010003

Received: 31 October 2020

Accepted: 23 December 2020

Published: 27 December 2020

Publisher's Note: MDPI stays neutral with regard to jurisdictional claims in published maps and institutional affiliations.

Copyright: (c) 2020 by the authors. Licensee MDPI, Basel, Switzerland. This article is an open access article distributed under the terms and conditions of the Creative Commons Attribution (CC BY) license (https: / / creativecommons.org/ licenses/by/4.0/).

\begin{abstract}
This article expands the evidence about integrative thinking by analyzing two case studies that applied the collaborative decision-making method of deliberative democracy which encourages representative, deliberative and influential public participation. The four-year case studies took place in Western Australia, (1) in the capital city Perth and surrounds, and (2) in the city-region of Greater Geraldton. Both aimed at resolving complex and wicked urban sustainability challenges as they arose. The analysis suggests that a new way of thinking, namely integrative thinking, emerged during the deliberations to produce operative outcomes for decision-makers. Building on theory and research demonstrating that deliberative designs lead to improved reasoning about complex issues, the two case studies show that through discourse based on deliberative norms, participants developed different mindsets, remaining open-minded, intuitive and representative of ordinary people's basic common sense. This spontaneous appearance of integrative thinking enabled sound decision-making about complex and wicked sustainability-related urban issues. In both case studies, the participants exhibited all characteristics of integrative thinking to produce outcomes for decision-makers: salience-grasping the problems' multiple aspects; causality-identifying multiple sources of impacts; sequencing-keeping the whole in view while focusing on specific aspects; and resolution-discovering novel ways that avoided bad choice trade-offs.
\end{abstract}

Keywords: sustainability; deliberative democracy; mini-publics; integrative thinking; participatory budgeting; Western Australia; Perth; Geraldton

\section{Introduction}

Life in cities, where the majority of human population now lives, is complex with a myriad of influencing elements, many interrelated factors and unknowns [1]. Complexity is a characteristic of a system whose components "interact in multiple, nonlinear ways without direction" and although the outcomes of these interactions cannot be predicted, particular patterns of behavior can be identified [2] (p. 5). The prevailing paradigms of economic development, growth and consumption not only further exacerbate this urban complexity but also contribute towards climate change, biodiversity loss, and ineffective use of natural resources, ultimately making cities vulnerable and exposed to social and environmental conflicts. This transforms urban complexity where possible solutions can be sought from multiple and often conflicting perspectives, into wickedness in which there is lack of agreement about the essence of the problems, approach for solving them or responsibility because of many potential causes, stakeholders and implications [3]. Wicked urban problems are compounded by the physical complexity of city life with the need to re-incorporate the human and social dimensions into the process of finding solutions [4]. In fact, Conklin et al. [4] argue that wickedness is not about increased complexity, although complexity continues to exist, but about a different type of challenge where developing an agreement about the problem takes lead ahead of looking for possible solutions. According to Bussmann [5], solving a wicked problem is fundamentally a social process in which 
complexity persists. Complexity arises from the dynamism during the identification of the wicked problem's nature and in the search for solutions, and is represented through the array of stakeholders holding diverging, often conflicting, views and perspectives [6].

Sustainable development, including as delineated in the global Sustainable Development Goals (SDGs) and SDG11 of Sustainable Cities and Communities, represents a prime example of wicked problems. The search for solutions requires the human elements to play a leading part in identifying the problems in order to direct the pursuit for possible social, technological, economic and policy transformations. However, wicked problems and specifically achieving the SDG11 targets in making human settlements more resilient, inclusive, safe and sustainable, require a different way of thinking that breaks off with the existing leadership paradigms and participation practices and looks for new forms of direction rooted in the collective wisdom of the human race.

Complex and wicked issues, such as urban planning, cannot easily be pulled apart for solutions to be put in place as people and events interact, are interconnected and constantly evolve [7]. Within a sustainability agenda, such transformation needs to generate a transition to better environmental, social and economic functions and performance of the cities. The new thinking needed for dealing with wickedness, however, requires different mindsets, ability to tolerate ambiguity, reassessment of expectations and an open-minded approach [7]. It is also described as intuitive and representing "basic common sense" [7] (p. 2). According to Conklin and Weil [6] (p.3), this process of thinking looks "like a seismograph for a major earthquake" with a pattern that appears chaotic, opportunity-driven and with unpredictable leaps. However, what emerges is "a natural learning process" [6] (p.3), that is intuitive and ultimately represents "basic common sense" [7] (p. 2).

Martin [8] describes the rational process used for finding solutions to complex or wicked problems as integrative thinking. According to him [9] (p. 13), integrative thinking is: "The ability to face constructively the tension of opposing ideas and, instead of choosing one at the expense of the other, generate a creative resolution of the tension in the form of a new idea that contains elements of the opposing ideas but is superior to each." He further explains that a linear approach in decision-making presumes that only one solution exists while in reality, the world is more complex, with multiple options existing simultaneously. With integrative thinking, solutions can be generated that do not require us to choose, for example, between the economy and the natural environment or between ethical and business values. According to Douglas [10], integrative thinking combines logic, intuition and creative imagination to create holistic solutions while Benson and Dresdow [11] emphasize that this process is enriched by common sense.

Integrative thinking exhibits four defining characteristics [12]:

(1) Salience-instead of seeing only a single aspect or component of the problem as having primary, even overriding, importance, this type of thinking brings the attention to several that deserve careful consideration;

(2) Causality - this thinking grasps the problems as not having a single, direct cause or explanation, but instead being the result of multiple factors, each of which contributes something substantial to their nature and shape;

(3) Sequencing-integrative thinking keeps the whole of the problem in view while focusing on specific parts; it does not become preoccupied with the latter to the point of losing sight of the overall situation that must be addressed or the overall goal to be achieved; this allows for the specific aspects to be arranged in a particular way that provides a better understanding of the whole; and

(4) Resolution-integrative thinking accepts that there is a downside to every potential solution represented through costs, disadvantages, undesirable (and often unforeseen) consequences; therefore reconciling competing values inevitably involves trade-offs; however, it does not dwell on the trade-offs but instead tries to imagine solutions that offer an acceptable balance between desirable and undesirable aspects, keeping the worst at bay while achieving as much good as possible. 
There are two important aspects of integrative thinking that deserve some attention. The first is its empirical foundations in pragmatism and the second is who is capable of demonstrating such a mode of thinking.

First, Martin [9] developed the elements of integrative thinking based on interviews with successful leaders from industry, the arts and the not-for-profit sector arguing that these people can simultaneously maintain opposing ideas in their mind in order to creatively generate a superior solution. As with many concepts influenced by pragmatism (e.g., [13-15]), the justification for integrative thinking is based on accepting evidence that works [16]. With sustainability being characterized by wicked problems, integrative thinking is able to integrate reason and logic based on empirical evidence and scientific understanding but also imagination and ability to create a better vision for the future. If the empirical evidence shows that integrative thinking works in finding solutions to complex and wicked problems, then it should be highly encouraged. Furthermore, Poth [2] provides a practical guide to integrative thinking as a research method to understand reality.

Second, the original work which recognized integrative thinking was based on identifying such skills in leaders. Karakas and Kavas [17] see it as a most needed skill for the 21st century managers. However, the size and urgency of the sustainability imperatives within urban environment pose big challenges: do we wait for such leaders to come forward or is it possible to create circumstances that encourage integrative thinking? According to Kallio [18], interest in adult thinking has occupied a range of disciplines, including philosophy, psychology and pedagogy. Despite the many theoretical and empirical difficulties to explain mature cognition and intellectual capacity, she argues that at their core is the capacity to integrate [18]. Alexander and Langer [19] (p. 27) define integration as a form of thinking "that integrates several opposing systems into an abstract whole that contains all particulars". When people develop an understanding of a problem, from an epistemological point of view they coordinate different sources of knowledge, including expert advice and personal experience [20]. In this process, different components of the psyche are also integrated, such as emotion, thinking and conation [18]. Kallio [18] concludes that integrative thinking is the most apt manifestation of adult development which takes place in a social environment shaped by diverse paradigms and values [21].

If solving wicked problems is based on natural learning during the process of defining the problems, is it possible that not only leaders (as claimed by Martin [9]), but also ordinary people (as explained by Kallio [18]) can bring integrative thinking and experience into decision-making processes that define the future of the urban environments where they live? An essential question that arises then is related to what circumstances can allow for integrative thinking to emerge. To make urban environments more sustainable, it is important to create the conditions which trigger integrative thinking and lead to improved sustainability.

The main aim of this study is to investigate whether initiatives in deliberative democracy can stimulate integrative thinking and generate better decision-making for making cities more sustainable. It uses two long-term Western Australian case studies, the analysis of which generates a better understanding about how sustainability can emerge from the wisdom of ordinary people who tackle complex problems with common sense. In essence, it brings together complexity and wickedness with integrative thinking and deliberation to create better decision-making in urban planning and governance.

Section 2 discusses deliberative democracy and outlines some of the methods it employs. This is followed by Section 3 which explains the use of case studies as an investigative method and introduces the two Australian locations where they were conducted. Section 4 presents the results from the case studies and Section 5 discusses these outcomes. Conclusions and some final remarks about the opportunities presented by this approach are given in Section 6. 


\section{Deliberative Democracy}

Deliberative democracy can be defined as a "form of collective decision-making about policy issues, in which a group thoroughly analyses a problem, scrutinizes proposals that reflect a variety of perspectives, and then chooses a well-reasoned solution" [22] (p. 275), with the outcomes influencing policy development or decision-making [23]. It began as a school of thought within political theory which argues that public deliberations of issues should be a defining characteristic of democracy [24]. In fact, deliberative democracy is a normative political theory that stipulates how political practice should occur, rather than explaining it [25]. In order to demonstrate and facilitate public engagement through fair and reasonable discussions and debates, deliberative democracy has now developed a range of tools-methods and techniques, based on principles, such as representativeness, deliberativeness and influence [26]. These various deliberative methods and techniques are now applied across the globe, a phenomenon described by the Organization for Economic Co-operation and Development [26] as a "deliberative wave".

Deliberative democracy has become an established way of creating egalitarian spaces to engage with citizens who represent the broader population of a place, by deliberating and resolving issues of importance, with the outcomes influencing decision-making [22,23,27]. Success is heightened when decision-makers publicly commit to the influence the deliberation's outcomes will have on policy development and decision-making. Respectful communication and trust building are essential in order to work in partnership to deliver possible solutions on complex issues [27]. According to Curato et al. [28], deliberative democracy is a realistic way to handle tension in a democratic society and can be a way of engaging with all sections across the community, including dealing with social division, marginalization and exclusion, to produce pluralistic outcomes.

\subsection{Deliberative Methods}

Diverse methods are deployed to design, conduct and analyze deliberation. Standard social science methods, such as surveys and interviews, are employed to set the scene initially, and measure the shifts as a result from the deliberations (e.g., [27]). In terms of the design and implementation of deliberative democracy initiatives, numerous innovative public participation techniques have been developed aimed at achieving carefully reasoned decision-making about a broad range of complex and wicked problems. They all allow for decision-making outcomes to emerge and include among others citizens' juries, citizens' assemblies, deliberative forums and participatory budgeting [29]. Below is a succinct overview of the deliberative methods used in the two case studies analyzed in this paper.

\subsubsection{Deliberative Forums}

Deliberative forums are convened to create a space for deliberation on issues of importance. The deliberation is carried out by a mini-public - a demographically representative sample of the population affected by the issue on the agenda for the forum [30]. Typically, the mini-public consists of citizens chosen through stratified random sampling to participate in the forum, with a view to ensuring that those selected reflect the demographic diversity of the larger population. When the forum is conducted in a physical (as compared to a virtual) space, there may be limitations to the mini-public being statistically representative of the population; however, diversity in terms of a stratified random sampling including variables, such as age, gender, ethnicity, education etc., is maintained.

The deliberation usually involves several phases: (1) learning about the issue; (2) considering and thoroughly discussing the issue and devising options for moving forward; and (3) reaching informed, considered, collective decisions or recommendations [31]. For example, after learning from experts and deliberating the issues between themselves, the mini-public participants may be asked to compile a list of possible solutions to the problem, discussing and identifying their pros and cons; then after determining the values that matter to them regarding the issue at hand, they may be asked to weigh the options against 
the values, and rank them to arrive at a coherent way forward that is cogent enough to influence policy-making decisions [32].

To enable the learning phase, experts holding particular knowledge, diverse perspectives and/or representing stakeholders, inform the mini-public about the various aspects of the issue. They offer facts and data and respond to questions, so building up participants' knowledge and critical thinking skills. These learning sessions help to establish respectful comprehension both of each other's views and of the diverse experts. They also dispose the mini-public participants to accept and acknowledge the tensions between viewpoints and the necessity of deliberating - weighing the advantages and disadvantages of different responses to the problem-in order to identify the solution that will best meet the concerns and needs of everyone.

Facilitators (on small tables or small online groups) are used to enable the forum deliberation to run smoothly with maximum engagement of all participants. They follow well-established facilitation protocols (e.g., [33]). The demographic representativeness of the mini-public would count for little if some perspectives were ignored, misconstrued, met with skepticism or even hostility. For this reason, the facilitators ask participants to adopt discursive norms that emphasize the entitlement of each to equal consideration and respect from others as they attempt to explain and justify the perspectives to which they subscribe. Of these norms, the most important is the one that asks participants to engage in a dialogue rather debate- that is, to listen carefully to each other in an effort to gain clarity and understanding rather than to contradict or refute statements in an attempt to secure a rhetorical advantage. Dialogue encourages participants to understand and appreciate the various values, concerns, needs and experiences that different perspectives comprise. Facilitators often ask the participants to focus on "and" rather than "or" responses during their conversations, enabling a safe environment for creative as well as critical thinking.

A report, entitled participant report, is produced at the end of the deliberative forum which contains the results from each phase of the deliberation, and concludes with the ways forward recommended by the participants. The aim is for the deliberative forum to generate outcomes which the participants can then deliver to the respective decisionmakers for actioning.

Each of the techniques applied under the general heading of deliberative forum focuses on a different way to achieve a deliberative outcome. In the two case studies, these included citizens' juries, citizens' assemblies, deliberative polls, multi criteria analysis deliberations and 21st century deliberations; and in the 2nd case study, also a particular form of participatory budgeting [29].

\subsubsection{Participatory Budgeting}

The best known and most remarked upon invention of deliberative democracy is participatory budgeting, now practiced in around 3000 places across the globe [34]. Participatory budgeting involves civic groups devising proposals and the broad community voting on their preferences to allocate a fraction of a local budget. This fraction can be around $5 \%[35,36]$ or higher, with a larger number representing a more fundamental and far-reaching change in the way the budget is developed and used. A variation of this method, used predominantly when $100 \%$ of a budget is allocated by a mini-public, has been termed the Australian Participatory Budgeting method.

In participatory budgeting processes, the involved officials may announce in advance the degree to which or the ways in which the participatory outcomes will influence their decision. Participatory budgeting can also be institutionalized as a public policy [34], mainly at a local government level [37]; however, this is not the case in Western Australia.

\subsection{Application of Deliberative Democracy}

Many examples exist across the globe where deliberative democracy has delivered better urban decision-making. In 2017, the Madrid City Council in Spain held its first G1000 conference. From a pool of 10,000 households, with one person per household 
volunteering to participate, a randomly selected group of 30 to 50 persons was selected to resolve either an issue of importance that the City's government has been unable to settle or one that participating citizens deemed to be of importance [38]. Though oneoff initiatives are useful, continuity of deliberative democracy in each urban setting is needed to achieve consistently better sustainability decision-making. One example of this is the State of Oregon's (USA) Citizens' Initiative Review (CIR) which is now a permanent institution authorized by an act of the state legislature [39]. In the CIR, a panel is convened each time a voter-instigated initiative succeeds in being placed on a ballot. Randomly selected citizens query a broad range of experts and stakeholders and deliberate with a view to composing the text of the official State Voter's Guide containing the 'pro' and 'con' arguments concerning the initiative [40]. In the Australian state of Victoria, the 2020 Local Government Act institutionalized deliberative engagement in the development of each local government's Community Vision and three major plans-Council Plan, Financial Plan and Asset Plan [41].

The challenges of 2020 saw further expansion of deliberative democracy to tackle issues, such as a post-COVID-19 world-deliberations conducted in Oregon via Zoom, and France's cutting of greenhouse gas emissions by 2030 [42]. In each example, the deliberative democracy initiative has been aimed at resolving a complex or wicked problem. Drawing on 289 successful cases, the OECD Report [26] concludes that when properly conducted, deliberative democracy can deliver better policy outcomes, though it does not elucidate exactly why this was the case.

Deliberative democracy initiatives have been described as a "trigger" to improve reasoning and listening [43]. A question that may be raised is under what conditions deliberative democracy methods can deliver a different way of thinking among the participants that results in success rather than failure in addressing complex problems. Previous research shows that processes which put into effect the deliberative norms of being inclusive, consequential and authentic improve participants' ability to address the complexity of political discourse [44,45], including integrative complexity [46] and deliberative reasoning [47]. According to Niemeyer [48], the key to improved reasoning and decision-making is the quality of the deliberative norms being practiced. Hence the challenge is to design and implement initiatives grounded in the above deliberative norms that engender informed judgements based on open-mindedness, listening, learning, creative and critical thinkingdiscourse that seeks common ground rather than a preoccupation with argumentation.

\subsection{Deliberative Democracy and Integrative Thinking}

Social sciences are yet to fully deal with wickedness; however, psychology has been able to bring together complexity and integrative thinking in the concept of integrative complexity - a measure of an individual's style of thinking, including the way information is processed, problems are solved and how decisions are made [49]. While complexity analyzes the structure of a person's thoughts, irrespective of their content, integration examines the ability to perceive and make cognitive connections between different perspectives [50]. People with higher integrative complexity "construct more accurate and balanced perceptions of other people, notice more aspects of the environment, use more information when making decisions" [51]. However, research has also found that such a way of thinking is not a stable personal characteristic and can be affected by many factors related to the situation or the social environment [51]. In fact, measuring integrative complexity may help predict outcomes in extreme situations, such as wildfires [52] or international crises [53].

It is important then to understand how integrative complexity manifests during deliberative democracy exercises, such as deliberative forums and participatory budgeting. Previous research carried out in Sweden has categorically indicated that integrative complexity increases as a result of participation in deliberative mini-publics [46]. The participants demonstrated greater recognition of complexities, they acquired new skills to deal with conflicting views and ambiguity, their mindset also was modified [46]. 
What is of interest in this study however is not just the individual performance of the participants during deliberative mini-publics, but whether as a discursive group, they were able to produce better urban decision-making. The results from two Western Australian case studies are discussed below from the perspective of the integrative thinking which emerged during the deliberative processes and became reflected in the outcomes of these deliberations.

\section{Materials and Methods}

This article analyses the application of deliberative democracy in two case studies from Western Australia-one centred in the State's capital Perth and its metropolis, and the other based in the regional city of Greater Geraldton. According to Yin [54], case studies are a powerful way to conduct an empirical investigation of a particular phenomenon within its real-life context. George and Bennett [55] further expand this definition by emphasizing that the investigator's aim is to investigate a theory regarding the studied phenomenon. Using a case-study approach is an established research design which is applied across a broad range of disciplines [56], from medicine to social sciences and law. In this article, we investigate the theory of integrative thinking by analyzing two case studies, both charged with resolving urban sustainability challenges. A common characteristic of the real-life circumstances of both case studies is that the problem solving, decision-making processes embraced deliberative democracy.

Before we proceed with the description of the two case studies, it is important to address how perceived limitations of this research method [56] are addressed. By selecting case studies where deliberative democracy methods were used, we allow for similarities/differences to be drawn in order to conduct a theory-led investigation. Transparency in the urban planning and research processes was consistently maintained to expose all participants to the same relevant and meaningful information and decision-making frameworks. This added rigor to the interpretation of the outcomes from the planning processes. All deliberations concluded with a tangible outcome. At the end of each deliberation day, reports in participants' own words were disseminated to all involved, as well as a concluding Final Participant Report. This created transparency and trust, continually allowing for verification of the data and planning recommendations.

\subsection{Case Studies}

The Perth case study was conducted between 2001 and 2005 and the Greater Geraldton case study between 2011 and 2015. Though relatively old, these case studies were selected both because of their distinctive and similar characteristics which make them particularly useful to explore the relevance of integrative thinking to more implementable decisionmaking regarding sustainability challenges.

\subsubsection{Perth Case Study}

The capital of Western Australia, Perth, with a population of around 1.5 million, is an automobile-dependent city [57] which operates a commercial port servicing the State's resource-based economy. The port generates a large volume of road traffic causing street congestion, noise and pollution. On the other hand, the port plays an important role for the State's economy as a major point of exports and imports in a place that is geographically isolated. Additionally, urban growth, together with the continuing demand for single dwelling housing has resulted in an increasingly sprawling metropolis and, given the car dependency, has exacerbated urban unsustainability.

In order to resolve the conflict between the needs of the State's economy, the road situation, and the provision of healthy urban environments in the Perth and the surrounding Peel Region, the Minister for Planning and Infrastructure committed to using deliberative democracy processes to improve the planning of the urban metropolis. A number of deliberative initiatives were undertaken between 2001 and 2005 to resolve complex planning and infrastructure issues in the interest of achieving improved sustainability and livability 
in Perth and the surrounding region. These multi-year initiatives covered topical issues and built on each other. The first was related to the use of road trains-long trucking vehicles with several trailers or semi-trailers, transporting containers and other merchandise to and from the port. It led to deliberative discussions about revising the freight network of Perth and consequently, the entire design of the capital city. The latter deliberations were named "Dialogue with the City" and addressed the fundamental question about what kind of place Perth's residents wanted to live in and how should Western Australian capital look into the future.

All initiatives were based on convening mini-publics-randomly selected members of the public demographically representing Perth's population. Some also included representative stakeholders and self-nominees responding to local advertisements, to ensure all viewpoints would be considered. In each deliberation, participants were purposefully seated to maximize diversity. Where stakeholders and self-nominees participated in the deliberations, the randomly selected participants outnumbered the others; also, table facilitators were trained to ensure no one's voice dominated. Feedback surveys conducted at the conclusion of each deliberation, consistently showed high participant satisfaction with the deliberative process, in particular with having a voice and being heard. The mini-publics utilized multiple deliberative tools including technological platforms to collect all ideas, theme, prioritize and conduct multi-criteria analysis and collaborative mapping. Prior to a number of the mini-public deliberations, large scale surveys of urban residents were conducted regarding salient sustainability issues. The results were made available to all participants for them to understand the broader community's views of the issues under discussion. These mini-publics culminated in a large-scale 21st Century Town Meeting"Dialogue with the City", with 1000 participants, deliberating in small groups, and using a mapping game, to create the city they wanted. Each mini-public, including "Dialogue with the City, resulted in a tangible outcome-planning solution recommendations-which were then delivered to the Ministry of Planning and Infrastructure. An important condition for the success of the deliberative decision-making was the prior commitment by the Minister to adopt the outcomes from the deliberations or champion the findings in the Ministerial Cabinet if there was joint responsibility for implementation.

\subsubsection{Greater Geraldton Case Study}

Located next to the Indian Ocean, $400 \mathrm{~km}$ north from Perth, is the City of Greater Geraldton-an area covering the regional city of Geraldton together with the towns of Mullewa and the historical Greenough, with a population of around 40,000. The region has a resource-dependent economy dominated by mining and agriculture, which, together with climate change, proffer significant challenges to the sustainability of the city-region. Each year its local government faces the challenging task of allocating a limited annual budget for different services and infrastructure needs of the city. Led by a sustainabilityoriented Chief Executive Officer (CEO), the local government wanted to involve those who lived and worked in the region to participate actively in understanding the challenges of developing a more sustainable city-region and finding ways to meet them.

A series of deliberative exercises were conducted between 2009 and 2014 which helped determine the most salient sustainability issues pertaining to Greater Geraldton and recommended ways forward. Prior to these deliberations, a large-scale survey of city-region residents was conducted to determine the most salient issues facing Greater Geraldton. Based on these results, a variety of deliberative techniques were used to develop a new structure plan for the city and region, a strategic community plan, and participatory budgeting for $100 \%$ of the local government's budget.

\subsection{Similarities and Differences between the Case Studies}

The Perth and Geraldton case studies were selected for (a) their similarities in terms of the ongoing use of deliberative democracy as a way to resolve a government's sustainability issues; and (b) their differences in terms of context, topic and methods used. 
In both instances, the government leadership determined that the cities had to change direction towards greater sustainability; and to achieve this, the people needed to be far more involved in understanding the problems/challenges involved and in recommending solutions. Furthermore, in both instances, the leadership championed deliberative democracy and publicly committed to the extent of influence of every deliberative democracy initiative. The culminating issues that were addressed in each case study were wicked; and importantly, the respective leaders expressed confidence that the empowered involvement of everyday people in considered discourse would enable them to resolve and implement solutions that had hitherto eluded them $[58,59]$. In each case, the very different form of these culminated in high impact deliberations that arose from its context. The Perth case study focused on involving very large numbers of participants to make the event too big to ignore (as had happened to all city plans to that date). In the case of Greater Geraldton, the mini-publics culminated in two in-depth deliberations-Australian $100 \%$ Participatory Budgeting, one lasting for four and the other for eight weeks, providing the time needed to resolve the highly contentious issue of the local government operational and infrastructure budgets which were in deficit [27].

Both case studies adhered to the underlying principles of deliberative democracyrepresentativeness, deliberativeness and influence (see Table 1). In addition, they both applied principles of adaptive management-responding flexibly and reflexively when unexpected sustainability challenges and opportunities emerged [60]. The latter approach inevitably led to many of the differences in the case studies in terms of their subject, scope, specificity and deliberative techniques adopted, as well as their methods of oversight and analysis (see Table 2).

Table 1. Similarities between the two case studies.

\begin{tabular}{cl}
\hline Element & \multicolumn{1}{c}{ Description } \\
\hline \multirow{2}{*}{ Method } & $\begin{array}{l}\text { Holding a series of different mini-publics leading up to } \\
\text { addressing a pressing wicked problem of that time. Each } \\
\text { mini-public was based on the same principles of } \\
\text { representativeness, deliberativeness and influence. Each outcome } \\
\text { built on the previous, culminating in a high profile, high value } \\
\text { initiative. }\end{array}$ \\
\hline Leadership & $\begin{array}{l}\text { Willing to champion and implement deliberative democracy to } \\
\text { resolve tough sustainability issues as they arose }\end{array}$ \\
\hline \multirow{2}{*}{ Charge } & $\begin{array}{l}\text { Urban sustainability, namely applying deliberative democracy to } \\
\text { address local urban sustainability issues, many of which were } \\
\text { wicked problems }\end{array}$ \\
\hline \multirow{2}{*}{ Community participation } & $\begin{array}{l}\text { Utilizing qualitative and quantitative participant evaluations; } \\
\text { qualitative evaluations with government officials; and external } \\
\text { reviewers' reports }\end{array}$ \\
\hline \multirow{2}{*}{ Facilitation } & $\begin{array}{l}\text { Inclusion of the broader community online and offline, as well as } \\
\text { issue stakeholders and experts }\end{array}$ \\
\hline & $\begin{array}{l}\text { Both of small-group deliberations (6-10 participants), and overall } \\
\text { lead facilitation by Janette Hartz-Karp (first author) following } \\
\text { established protocols }\end{array}$ \\
\hline Online platform & $\begin{array}{l}\text { Using an online platform enabling all participant ideas to be } \\
\text { collected, prioritized by individual participants or groups, with } \\
\text { information collated into a Final Report in a number of } \\
\text { mini-publics, and both of the culminating deliberations. }\end{array}$ \\
\hline $\begin{array}{l}\text { Partnership with the local/State newspaper in each locale to } \\
\text { publicize the deliberative democracy processes with fair } \\
\text { even-handedness, having been given continued observation } \\
\text { status of all deliberations and access to interview participants if } \\
\text { the latter agreed }\end{array}$ \\
\hline
\end{tabular}


Table 2. Differences between the two case studies.

\begin{tabular}{|c|c|c|}
\hline Element & $\begin{array}{l}\text { Perth Metropolis } \\
\text { "Dialogue with the City" }\end{array}$ & $\begin{array}{l}\text { City of Greater Geraldton } \\
\text { "100\% Participatory Budgeting" }\end{array}$ \\
\hline Aim and outcome & $\begin{array}{l}\text { Recommending a planning } \\
\text { strategy for a livable } \\
\text { City/region (Perth and Peel), } \\
\text { developed and co-owned by } \\
\text { those involved, presented to } \\
\text { the State Government Cabinet; } \\
\text { it was accepted in total }\end{array}$ & $\begin{array}{l}\text { Recommending and presenting to } \\
\text { Greater Geraldton Council the } \\
\text { reports for: (a) } 100 \% \text { allocation of its } \\
10 \text {-year infrastructure budget, and } \\
\text { (b) } 100 \% \text { allocation of its } \\
2014 \text { operational budget; all key } \\
\text { recommendations accepted }\end{array}$ \\
\hline Sustainability issue & $\begin{array}{l}\text { The capital city's need to more } \\
\text { sustainably respond to } \\
\text { population increases, reduce } \\
\text { city sprawl, car and truck } \\
\text { dependency, and create a } \\
\text { more livable city }\end{array}$ & $\begin{array}{l}\text { A budget in deficit, and an } \\
\text { Administrative Tribunal directive } \\
\text { for the City to work with the local } \\
\text { community to develop a more } \\
\text { sustainable budget }\end{array}$ \\
\hline $\begin{array}{l}\text { Culminating } \\
\text { deliberation }\end{array}$ & $\begin{array}{l}\text { "Dialogue with the City" } \\
\text { ( } 1 \text { day) - 1000 participants, } \\
\text { selected } 1 / 3 \text { via random } \\
\text { sample, } 1 / 3 \text { broad } \\
\text { stakeholder representatives, } \\
1 / 3 \text { self-nominations; (with } \\
3 \text { prior, separate } \frac{1}{2} \text { day } \\
\text { sessions for participants who } \\
\text { were Indigenous, young } \\
\text { people, and disabled) }\end{array}$ & $\begin{array}{l}100 \% \text { Participatory Budgeting for: } \\
\text { (a) Infrastructure } \\
\text { budget-30 randomly sampled } \\
\text { participants, } 4 \text { days duration; (b) } \\
\text { Operational budget- } 40 \text { randomly } \\
\text { sampled participants, } \\
8 \text { days duration }\end{array}$ \\
\hline Deliberation techniques & $\begin{array}{l}\text { 21st Century Town Hall } \\
\text { Meeting with a } \\
\text { Mapping Game }\end{array}$ & $\begin{array}{l}\text { 21st Century Town Hall Meeting } \\
\text { with Multi Criteria Analyses }\end{array}$ \\
\hline Online platform & $\begin{array}{l}\text { Developed by a Western } \\
\text { Australian IT company with } \\
\text { the ability to integrate scores } \\
\text { of mapping designs }\end{array}$ & $\begin{array}{l}\text { Developed by a US designer to } \\
\text { meet the needs of the Greater } \\
\text { Geraldton deliberations }\end{array}$ \\
\hline
\end{tabular}

\subsection{Analyzing the Case Studies}

The main method used to analyze the rich data produced during the two case studies is theory-driven retrospective qualitative analysis. At the time when the various initiatives were conducted in Perth and Greater Geraldton, the researchers were not testing any particular hypothesis as the focus was on generating pragmatic outcomes for complex and wicked urban planning problems. An advantage of the retrospective analysis approach is that the outcomes have already occurred, and this allows us to investigate the theory of integrative thinking for possible associations [61]. The relationship that this study retrospectively investigates is that between deliberative democracy and integrative thinking; in other words: has deliberative democracy generated an environment where integrative thinking emerges out of the efforts of ordinary people deliberating?

By having access to all data and documents produced during the deliberative initiatives, we were able to analyze whether the integrative thinking characteristics manifested in the two case studies. This was essentially document analysis during which the data were examined and interpreted "to elicit meaning, gain understanding, and develop empirical knowledge" [62] (p. 27). The outcomes from the two case studies helped provide a better understanding how deliberative democracy techniques can facilitate decisionmaking related to urban environments by allowing for integrative thinking to occur during the process. 


\section{Results}

The processes applied and outcomes achieved in these two case studies have stood the test of time. In fact, the processes have been taken up elsewhere and the outcomes are still relevant to increasing sustainability in their respective locales. Hence, they have become instructive places for the examination of how sustainability outcomes emerged, especially since the deliberative charges were not framed in terms of achieving transitions to greater sustainability. The frames created by the government proponents were very general- "Dialogue with the City", and "City of Greater Geraldton Participatory Budgeting Community Summit".

Improving urban decision-making almost inevitably involves wicked problems, which in turn, call for collaborative approaches if they are to be resolved successfully. However, these issues are rarely dealt with as wicked problems. Rather, the issues tend to be compartmentalized, following narrow streams of either/or thinking which inevitably limits their successful resolution. In these case studies, rather than relying on leader with extraordinary thinking and skills to resolve the issues, the approach was new. Deliberative democracy initiatives were applied, starting with smaller issues and building to resolving wicked problems. How everyday participants would achieve this was not the focus. It was presumed that if they participated in quality deliberative democracy processes, they would achieve implementable solutions. In short, although deliberative norms were explained and encouraged, facilitators and organizers made no attempt to outline let alone encourage participants to think any differently to their usual mode of thinking. It was only through reflexive thinking by participants, facilitators, organizers and external observers after the deliberations, that it emerged that together, the participants were exhibiting integrative thinking.

In both case studies, it became clear that the participants deliberating as mini-publics, together exhibited all the characteristics of integrative thinking as follows:

(1) Salience-they grasped the problems' multiple aspects;

(2) Causality - multiple sources of impacts were identified;

(3) Sequencing - they kept the whole in view while focusing on specific aspects in order to produce outcomes for decision-makers; and

(4) Resolution-novel ways avoiding bad choice trade-offs were discovered.

To explain how these results were achieved, a more detailed description of the methods used in these two case studies follows.

\subsection{Perth Case Study, 2001-2005: Culminating in Dialogue with the City}

A series of deliberative forums were undertaken in and around the Western Australia capital of Perth between 2001 and 2005. They began with consideration of a specific transport problem, but moved on to increasingly complex issues, including, ultimately, articulation of a consensual vision for the type of city people want to live in. Significantly, at each stage, the participants themselves called for the continuation and broadening of the discussions. Attempting to get to the bottom of specific problems and find possible solutions consistently revealed that a broader, more complex issue had to be addressed.

The initial deliberative exercise aimed to solve the longstanding problem with the running of exceptionally large and long road trains, driving down steep grades to the city's harbor. There was an announcement made by the State Minister for Planning and Infrastructure that, if the parties affected by the problem could reach agreement on how it can be solved, she would implement it. There were 150 participants who took part in the deliberative forum-one-third were randomly sampled residents from along the route in question; one-third consisted of other stakeholders, such as truck drivers, activist groups, industry, government and community representatives; and the remaining onethird comprised self-selected persons who responded to public invitations placed in shops, community spaces and in the media. The latter group was a way to include grassroots people who were interested in participating because of the existing newspaper publicity. This one-day deliberation began with presentations of different perspectives, followed 
by question-and-answer sessions. It was followed by a lengthy discussion session that emphasized listening in order to understand, not to debate. This raised awareness of the problem's multiple aspects (salience) and sources (causality). Next, the participants turned to the identification of a range of strategies and actions for dealing with those aspects and their sources (sequencing). They discussed which strategies were unacceptable, which they could live with, and finally, those they favored (resolution).

One of the key recommendations generated by the participants was for the State to establish a freight network review which would optimize the movement of products to the port (salience, resolution). To this end, a second set of deliberations were conducted in the capital city and the regions, with the results of previous events being reported to the participants in subsequent ones. Through this iterative process, a broad-based plan was developed for transporting goods from across the State to its key port, relying less on roads and more on rail. Thereafter, a plan of action was devised by a group of participant volunteers and was accepted by the Western Australian government (sequencing, resolution). This plan was both innovative, e.g. proposing to establish inland "ports" in critical locations to reduce road traffic, as well as implementable, i.e., the recommendations were considered feasible by and acceptable to government (resolution).

The third deliberative phase involved a multi-criteria analysis to determine the best route for solving a contentious and critical transport problem that remained: a section of main road planned decades earlier that crossed and divided valued wetlands, causing an unremitting public outcry. As part of the multi-day process, the broader public was given information about concerns and opportunities (salience, causality) and were invited to suggest alternative route options. Around 150 participants at the public deliberation then discussed and selected from the suggested options and added their own, yielding a total of 29 options and 30 evaluative criteria (covering economic, social and environmental aspects). A small team consisting of experts and participant representatives applied the criteria to each option using both quantitative and qualitative information. Finally, the participants weighted the options, and a computerized priority listing was produced (sequencing). The Government adopted the participants' top preference (resolution).

Notably, the forum participants also recommended a still broader, more complex deliberation be undertaken to address the fundamental question of what the city-region of Perth should look in the future. This process, called Dialogue with the City, commenced with a community survey sent to 10,000 citizens (salience); newspaper articles published on the front page of the daily newspaper over several weeks outlining problems and viewpoints (causality); a one-hour TV program in prime time on a commercial channel highlighting several growth options (salience, sequencing); and a series of options papers inviting social media commentary (salience, sequencing).

The culmination of the prior processes was a deliberative forum with more than 1000 participants. They developed themes and prioritized them (causality, sequencing). Another creative technique was a mapping game that enabled participants to develop a group map of the City-Region in 2030 (salience, causality, sequencing, resolution). Subsequently, almost 100 participant volunteers worked in small teams over a six-month period to develop the plan for the City-Region. The resulting plan-called Network City, transparently reflected the underlying principles and key directions forward recommended by participants in the deliberative forum (sequencing, resolution). Significantly, the plan was accepted by the State Cabinet. No such option had been seriously considered or even put forward previously by the State Planning Department.

Moreover, Network City offers a more sustainable way for Perth to grow by limiting urban sprawl and automobile dependence. It continues to be the plan driving the Perth City-Region's development today, over 15 years later. It has survived precisely because it resolved the dynamic tensions of a wicked problem in a way that was both innovative and implementable (sequencing, resolution) through integrative thinking. 


\subsection{Greater Geraldton Case Study, 2009-2014: Culminating in 100\% Participatory Budgeting}

In the initial stages of the case study, the CEO placed sustainability clearly on the agenda. However, what was surprising both to the CEO and the elected Council Members was the push for the region to become carbon neutral - a concept that had not previously been proposed or promoted at local government level. The Greater Geraldton deliberations began with a deliberative poll. A comprehensive survey was sent out to 2000 residents selected at random, 150 respondents agreed to also participate in a one-day deliberative forum that followed. The day was spent learning about key issues from different perspectives, achieved by querying experts who represented a range of viewpoints and through facilitated dialogue in small-group sessions (salience, causality, sequencing). At the conclusion of the day, the participants were asked to complete the same survey. An independent analysis of the pre and post surveys showed a significant increase in the participants' desire for the Council to more proactively improve the City-Region's sustainability, including becoming carbon-neutral (resolution).

Carbon neutrality was taken up by the participants in a further stakeholder deliberation involving representatives from all components of the national energy supply chain. Because the Geraldton region is extraordinarily well-endowed with solar, wind, geo-thermal, bio-mass and tidal energy sources (salience, causality), the participants deliberated the possibilities (sequencing). For the first time in Australia, a joint renewable energy plan was developed, agreed to, and submitted to the Federal Government (resolution).

Further deliberation occurred around the development of new Structure Plans for the city-region. A large-scale deliberative enquiry-by-design was conducted involving 250 residents, one-third randomly selected, one-third self-selected, and one-third invited as representatives from diverse stakeholder groups. They deliberated over three days in parallel with a multidisciplinary team of experts who translated the residents' ideas into six alternative plans (salience, causality). The participants then selected the elements from those plans they wanted to keep and identified the ones they wanted to change (sequencing). In response, the design team developed three options which were assessed and amended by the participants until they agreed on a consensus favorite (sequencing, resolution). This became the foundation of Greater Geraldton's City-Regional Structure Plan.

Throughout these deliberative processes, participants once again surprised both the elected Councilors and City administrators, by assigning priority to actions that first and foremost protected and nurtured the ocean, rivers and mountain ranges (sequencing). Next, they turned to sustainable city living by developing higher density urban nodes (to prevent sprawl) that could support local employment and public transport. These plans, too, differed substantially from those previously put forward by the City's administration. The participants had creatively resolved the inevitable dynamic tensions between social, economic and environmental concerns (resolution).

As all local governments in Western Australia were required to develop a Strategic Community Plan that would drive their budget, policies and planning processes, the City of Greater Geraldton's plan integrated the results of all prior deliberative democracy initiatives, reflecting the basic principles, the importance and urgency of key strategies and time-lines (salience, causality, sequencing, resolution). City officials and independent assessors judged this plan, together with the projects included and supported through it, to be more inclusive, integrated and innovative than prior plans and indeed those developed by other local governments. In 2014, this process won the International Association of Public Participation Project of the Year award for Australasia.

The culmination of the work in Greater Geraldton was the 100\% participatory budgeting triggered by a court case of local residents against the City's administration for increases in rates and taxes to collect more revenue. As the people of Greater Geraldton were already used to joint problem-solving and decision-making, they resented not only the economic burden of higher taxes, but also what appeared to be back-tracking by their elected members in terms of enabling empowered participation to resolve issues that 
mattered. The State Tribunal's mediation process resulted in the City's administration committing to $100 \%$ participatory budgeting (PB).

Two PB panels were conducted-the first to allocate $100 \%$ of the City's 10-year infrastructure budget, and the second to allocate $100 \%$ of its annual operational budget. This was the first case in the world where randomly sampled participants determined $100 \%$ of both the operational and infrastructure budgets of a government. Using a mini-public to determine $100 \%$ of a budget is now known as the Australian Participatory Budgeting method.

The first PB Panel consisted of a stratified random sample of 30 participants living and working in Greater Geraldton. Its panel members deliberated over five Saturdays to make recommendations on the allocation of over AUD $\$ 70$ million representing the 10-year infrastructure budget. The panelists carefully considered infrastructure proposals put forward by the City's administration, residents and civic groups who had been invited to submit proposals (salience, causality). All proponents were queried by the PB Panel regarding the importance of their project, its rationale, timing and likely effectiveness in achieving the desired result (salience, causality sequencing). Through extensive deliberation, the Panel members determined the criteria they would use to prioritize the projects. Each criterion was a combination of several, often opposing ideas (salience, causality). For example:

- The project supports future population retention and growth while maintaining affordable living;

- The project supports our 'Gero' (a nick name for Greater Geraldton) lifestyle—big city amenities while retaining a small-town feel; and

- The project yields substantial community benefit compared to the financial cost.

The criteria exemplified the emphasis integrative thinking places on the creative management of diverse ideas rather than struggling to weigh trade-offs. They acknowledged competing values and priorities and respected the different perspectives people hold. In response, each made possible a novel solution in the form of an innovative option. Despite some opposition by the CEO to the use of such criteria, an independent statistician determined that the results met validity and reliability requirements, and the PB Panel resolved to retain them. The PB Panel also recommended that its criteria be applied to only $50 \%$ of the final budgetary allocation, with the priorities of the City's administration accounting for the remaining 50\%. Subsequently, the Council accepted all of the PB Panel's recommendations (resolution) delivering 100\% participatory budgeting. The PB Panel's response thus illustrates how tensions between values, principles and priorities can be resolved, providing conditions are established that are conducive to integrative thinking.

A second PB Panel made recommendations for the allocation of the 2013-2014 operational budget (also over AUD $\$ 70$ million). It was charged with recommending a balanced budget. A group of 40 residents constituting a stratified random sample of the local population deliberated for over eight Saturdays. To help the panelists understand not only the complexities of operational budgeting, but also the costing of the extensive range of services delivered, the City's administration radically altered its presentation of budgetary information. The participants wanted to see a pie chart of the costs of overall services, and not the lists of costs submitted by the different administrative sections of the City. This task took the City's personnel, working with the assistance of external consultants, a month to complete. Nevertheless, this method is now used for all budgeting carried out by the City (salience, causality, sequencing).

The second PB Panel process resembled the first, but in this instance, the participants queried the City's officials responsible for each of its public services. They frequently asked for clarification of the need for the service, the costs of its components, feasibility of alternative modes of delivery and probable consequences of reducing or increasing funding (salience, causality). Notably, a number of elected Councilors attended each deliberation day of the Panel as observers. To support their requests for observer status, they explained that, for the first time, they had begun truly to understand the City's budgeting process and the value proposition of the provided services (salience, causality). The elected Council 
accepted all recommendations by the PB Panel on whether to retain, reduce, increase or discontinue services (resolution).

In both case studies, it becomes apparent how each deliberative initiative built on the one preceding it, enabling choices and decisions with bigger scope and greater depth than would have occurred had government alone undertaken to resolve each problem as it arose. This occurred, not despite frequent changes in direction, but precisely because deliberative democracy has the flexibility and staying power to adapt as economic and political conditions change. Deliberative processes became the default mechanism for responding to complex and wicked issues, largely because they enabled both citizens and government officials to keep the broader picture in mind, and demonstrated their capacity to help people develop systemic, sustainable solutions. Integrative thinking emerged from the inherent characteristics of deliberative democracy.

\section{Discussion}

In scientific research, it is often the case that comparisons are made between cases of success and failure or situations where deliberative techniques have been or not have been used. It is assumed that such comparisons can help identify the contributing factors and conditions under which deliberative democracy results in the emergence of the described integrative thinking dynamics. Although this may appear logical, it is an unreasonable expectation. As Rittel and Webber [3] (p.163) explained: “Every solution to a wicked problem is a 'one-shot operation'; because there is no opportunity to learn by trial-anderror, every attempt counts significantly ... One cannot build a freeway to see how it works, and then easily correct it after unsatisfactory performance." This is particularly the case with large-scale projects [63] as was the case with the development of a future plan for Perth and the allocation of $100 \%$ of the Greater Geraldton's budgets. In this sense, the planning initiatives in both, Perth and Greater Geraldton, are effectively irreversible. Any changes would again require dealing with another suite of wicked problems. Furthermore, all wicked problems are "essentially unique" [3] (p. 164) which means that despite any similarities, "there always might be an additional distinguishing property ... of overriding importance" because of the social dimension of wickedness. Creativity in finding solutions and judgement as to what is acceptable are at the core as of how wicked problems are resolved [64].

On the other hand, the mere existence of sustainability challenges, that is of wicked problems, indicates that the methods urban planners have employed in the past have not delivered satisfactory development. From that vantage point, there is much more merit in making historical comparisons for the same location and finding answers to questions, such: how does the public prefer planning and policy decision-making to occur? Would they prefer the most-used method where governments decide, having offered the public the opportunity to have a say or would they prefer plans and decisions to be made in partnership with government, e.g. via deliberative democracy? One indication that partnering is a better way of approaching wicked problems is the duration of our case studies, namely four years, in each instance at the request of the government leadership with the backing of the public. Another indication is that the deliberative democracy participants no longer saw the problem at hand as a siloed issue but rather as a multidimensional matter that required further deliberative democracy initiatives in order to resolve the broader aspects it raised. It is difficult to imagine wicked problems being resolved if those involved do not grasp that what they are dealing with is "wicked". Finally, research in Greater Geraldton [27] and across the globe [26] has shown that publics do indeed prefer a partnership relationship with government over other possible relationships.

Although these case studies have been previously analyzed [27,58,65-68], this is the first time when we specifically applied a theory-driven interpretation from the perspective of integrative thinking. In both case studies, deliberative democracy facilitated collective integrative thinking and generated solutions to wicked problems. As explained by Chwalisz [69], this was a better urban decision-making because of the following characteristics: 
- The deliberations resulted in considered judgements by the micro-publics rather than individual opinions-a wide-cross section of society (instead of self-selection) was covered through the principle of representativeness; the deliberations allowed for different opinions, as well as grievances, to be expressed, but they also became places of learning and sharing of knowledge and experiences. The majority of participants in Perth's Dialogue with the City indicated that they had broadened their understanding about the issues involved and about governance [65], and the following quote highlights the learning that occurred in Greater Geraldton: "I understand how hard they [the Council] work ... including the fact that they started this in the first place and they were willing to give it a go" [66] (p. 8).

- The deliberations provided greater legitimacy for bold choices to be made, such as the Network City plan for Perth and making Greater Geraldton carbon-neutral, which otherwise would have not happened because of the fear of political deadlocks or corruption claims. The legitimacy of the Network City plan for Perth was acknowledged by the Minister of Planning and Infrastructure [58] and the community vision for Greater Geraldton becoming carbon neutral was expressed in a Smart Cities Challenge submitted by the City's Council [68].

- There was increased trust in both directions-by the public in the government and vice versa - this was demonstrated exceptionally well during the design exercise for Perth and the participatory budgeting for Greater Geraldton. The detailed analysis of the mechanisms for repairing the political trust in Greater Geraldton [27] concludes that this was possible because of the established partnerships through the participatory budgeting initiatives. Similarly, Perth's Dialogue with the City created conditions for establishing trust by putting in place building blocks that synergistically delivered a search for consensus or common ground from a diversity of perspectives as well as the capacity to influence policy and decision-making [67].

- The deliberative processes energized the local communities and strengthened their integrity and willingness to counteract polarization and disinformation-among other things, these qualities were demonstrated with the continuous engagement in Greater Geraldton and the large level of participation (more than 1000 participants) in Dialogue with the City in Perth. The analysis conducted on Greater Geraldton's participatory budgeting shows that the gap between expectation and satisfaction from public participation was substantially reduced through the proper design and use of deliberative techniques [66]. Similar responses emerged in Perth with Dialogue with the City establishing an implementation team with six working groups and three liaison teams who coordinated the development of the new Network City planning strategy adopted by the Western Australian Government [67].

This research builds on two theoretical concepts to influence sustainability outcomes within urban environments. The individuals who participate in the mini-publics represent a microcosm of the whole population [70]. Any changes that occur at an individual level in the way of thinking in order to generate group outcomes are important. However, when it comes to sustainability it is the nature of the outcomes that matters more than individual shifts. To date, the importance of integrative thinking in addressing complex problems collectively through deliberative democracy has been an unexplored area. These two case studies demonstrate that the overall group outcomes resulted in major shifts towards more sustainable urban environments.

This change was brought about through deliberative democracy, a citizen-government partnering methodology, whose underlying principles and methods provide fertile ground for the development of integrative thinking. These two pioneering deliberative democracy processes in Western Australia offer grounds for entertaining a future scenario in which deliberative democracy enables more integrative public thinking and decision-making about sustainability issues. Potentially, this could foster the catalytic innovation in governance needed to help turn the curve toward greater sustainability. 
The power of deliberative democracy to deliver integrative thinking is manifested through the following aspects:

- Representativeness ensures that every perspective on the problem being addressed is guaranteed the opportunity to find full expression;

- Discursive norms during deliberation emphasize the entitlement of each to equal consideration and respect from others as they attempt to explain and justify the perspectives to which they subscribe. Of these norms, the most important is the one that asks participants to engage in dialogue rather debate as this expands the integrative complexity of their thought processes;

- The four characteristics of integrative thinking, namely salience, causality, sequencing and resolution, are manifested through group deliberations. Small group deliberation promotes mutual understanding and appreciation. This helps participants recognize that difficult public problems may have no complete, clear-cut, or universally acceptable solution, but at most can be mitigated and managed. Comprehension and acknowledgement of problem complexity and the mixed nature of the goods people desire help participants refrain from adopting a 'zero-sum' mentality, and instead pursue a pragmatic solution acceptable to all parties;

- For the public, knowing that the outcomes of their deliberation will influence policy development or decision-making encourages mini-public participants to move beyond narrow self-interest to take into account the good of the larger community. The prospect of contributing to a solution that works for ordinary people disposes participants to consider opposing ideas and to seek a way forward that incorporates elements of all positions but is superior to each on its own.

Each of these deliberative democracy initiatives inherently uses integrative thinking when participants understand the varying viewpoints, develop options, identify the tradeoffs between them, weigh the consequences of each against the values that matter to them, and arrive at a coherent way forward that is cogent enough to influence policymaking decisions regarding complex urban issues. Such deliberative processes have proven effective [71] and are exerting an impact on policy-making (e.g., [72]). As the two case studies show, when used over time, they are able to deliver better and more sustainable urban solutions.

It is important to emphasize that a defining factor for deliberative democracy initiatives to be successful is for them to be conducted adhering to the norms of being inclusive, consequential and authentic [44]. Inclusiveness refers to a wide spectrum of interests related to the particular issue being discussed and this was achieved in both case studies. Being consequential means that the outcomes from the deliberation will have consequences, in other words, they will have an impact on the making of policy decisions. Again, this was the case for both case studies. Authenticity describes deliberation processes that are non-coercive, stimulate reflection, exhibit reciprocity in presenting arguments in a way that others can accept, and connect particular claims to a more general picture and more universal principles [73]. This was the deliberative style in the case studies. If such deliberative norms are not being followed, any processes that claim to involve deliberation are unlikely to stimulate integrative thinking and be effective in generating positive outcomes. Both cases studies analyzed here strictly followed these deliberative norms in their design and engagement with participants and policy makers.

Another question that may be raised is whether the participants in the deliberations were individually socialized to adopt integrative thinking, in other words, whether the deliberative procedures made them behave in a way that was acceptable and encouraged by the particular settings. In these case studies, there was no purposeful attempt to encourage participants to think differently or in any particular way; yet it appeared that by thinking together while applying deliberative norms, integrative thinking occurred. Additional research is needed to further understand this. Additionally, it is interesting to know whether the participants individually shifted to a more integrative way of thinking following their participation in deliberative initiatives. These areas require further research 
since the two case studies analyzed here examined only the collective outcomes from the deliberative processes.

\section{Conclusions}

To address the challenge of rapid urbanization of populations that is exacerbating problems of unsustainability, and to transition to more sustainable settlements, we will need to adopt new ways of thinking and new ways of participating in building and maintaining livable cities. Integrative thinking - the creative resolution of tensions between competing values and priorities - offers a useful standard to guide us in resolving complex sustainability issues. The analysis of two cases from Western Australia-Perth, 2001-2005 and Greater Geradton, 2009-2014, in which deliberative democracy initiatives were continually used to resolve emergent sustainability challenges, shows that this form of partnership between the general public and decision-makers generates integrative thinking and delivers better urban solutions. The experiences and results of these two long-term participatory processes suggest that the principles and practices of deliberative democracy provide better decision-making through the spontaneous appearance of integrative thinking.

This mode of thinking explains to a certain degree the fact that deliberative democracy, through the collective intelligence and decision-making of mini-publics [42], has been able to deliver better policies to some of the most-pressing problems of this century which require value judgements, trade-offs and long-term vision [26]. The development and adoption of the Network City plan for Perth which fifteen years later remains the main planning document for the metropolis is a prime example. In the case of Greater Geraldton, deliberative democracy delivered the aspiration for the region to become carbon-neutral. Creating opportunities to scale out this methodology to ordinary citizens is a far lower-risk strategy for addressing sustainability challenges than waiting and hoping for effective leadership with the needed outlook and skills to save the day. This study demonstrates that deliberative democracy delivers better urban decision-making. However, to catalyze innovation capable of dealing with wicked problems and turning the curve toward greater sustainability will require deliberative democracy to become institutionalized, that is, for deliberative activities to be embedded in the rules of public decision-making and governance structures "in a way that is legally-constituted so as to establish a basic legal or regulatory framework to ensure continuity regardless of political change" [74], (p. 122). This will make deliberative democracy the "business as usual" way of resolving complex sustainability challenges.

Author Contributions: Both authors contributed equally in the conceptualization of the paper, its methodology, investigation and data analysis as well as in writing, reviewing and agreeing to the published version of the manuscript. All authors have read and agreed to the published version of the manuscript.

Funding: The research in Greater Geraldton was funded by an Australian Research Council Linkage Grant. The Perth case study was sponsored by the State Government of Western Australia while the Greater Geraldton case study was sponsored by its local government.

Institutional Review Board Statement: The study was approved by the Human Research Ethics Committee of Curtin University.

Informed Consent Statement: Informed consent was obtained from all participants in the study.

Data Availability Statement: No new data were created or analyzed in this study. Further information regarding data is available upon request from the corresponding author.

Acknowledgments: The authors acknowledge the invaluable contribution of all members of the public who participated in the deliberative democracy initiatives in Perth and Greater Geraldton. They are also thankful to the then Minister of Planning and Infrastructure and CEO of Greater Geraldton who were prepared to be informed in their decision-making by the outcomes from the deliberative forums and participatory budgeting. We also thank the Journal's editor and three anonymous reviewers whose comments helped improve the quality of the manuscript. 
Conflicts of Interest: Both authors declare no conflict of interest. The funders had no role in the design of the study; in the collection, analyses, or interpretation of data; in the writing of the manuscript, or in the decision to publish the results.

\section{References}

1. Kinni, T. The Critical Difference between Complex and Complicated. MIT Sloan Manag. Rev. 2017. Available online: https: // sloanreview.mit.edu/article/the-critical-difference-between-complex-and-complicated/ (accessed on 29 October 2020).

2. Poth, C.N. Innovation in Mixed Methods Research: A Practical Guide to Integrative Thinking with Complexity; Sage: Los Angeles, CA, USA, 2018.

3. Rittel, H.W.J.; Webber, M.M. Dilemmas in a general theory of planning. Policy Sci. 1973, 4, 155-169. [CrossRef]

4. Conklin, E.J.; Basadur, M.; VanPatter, G.K. Rethinking Wicked Problems: Unpacking Paradigms, Bridging Universes. NextD J. 2007, 10, 1-30. Available online: https:/ /issuu.com/nextd/docs/conv28 (accessed on 27 November 2020).

5. Bussmann, R. 'Wicked Problems'-Approaching the Complexities of Development Management. 2014. Available online: https: //www.academia.edu/7637821/Wicked_Problems_Approaching_the_Complexities_of_Development_Management (accessed on 21 November 2020).

6. Conklin, J.; Weil, W. Wicked Problems: Naming the Pain in Organizations. 2007. Available online: http://www.accelinnova.com/ docs/wickedproblems.pdf (accessed on 21 November 2020).

7. Nason, R. It's Not Complicated: The Art and Science of Complexity in Business; University of Toronto Press: Toronto, ON, Canada, 2017.

8. Martin, R. How to Solve Wicked Problems Using Integrative Thinking. 2010. Available online: https://www.youtube.com/ watch?v=cOGXhg8_aFc (accessed on 21 November 2020).

9. Martin, R.L. The Opposable Mind: How Successful Leaders Win through Integrative Thinking; Harvard Business School Publishing: Boston, MA, USA, 2009.

10. Douglas, G. Achieving Sustainable Development: The Integrative Improvement Institutes Project. Available online: https: //mpra.ub.uni-muenchen.de/14624/1/MPRA_paper_14624.pdf (accessed on 29 October 2020).

11. Benson, J.; Dresdow, S. Common sense and integrative thinking. Manag. Decis. 2009, 47, 508-517. [CrossRef]

12. Martin, R.L. Integrative Thinking: A Model Takes Shape. 2002. Available online: https://rogerlmartin.com/docs/default-source/ Articles/integrative-thinking/integrativethinking_amodeltakesshape (accessed on 29 October 2020).

13. Peters, T.; Waterman, R.H., Jr. In Search of Excellence; Harper \& Raw: New York, NY, USA, 1982.

14. Porter, M.E. The Competitive Advantage of Nations; Free Press: New York, NY, USA, 1990.

15. Putnam, R.D. Bowling Alone: The Collapse and Revival of American Community; Simon \& Schuster: New York, NY, USA, 2000.

16. Internet Encyclopedia of Philosophy. Pragmatism. Available online: https://iep.utm.edu/pragmati/ (accessed on 22 November 2020).

17. Karakas, F.; Kavas, M. Creative brainstorming and integrative thinking: Skills for twenty-first century managers. Dev. Learn Organ. 2008, 22, 8-11. [CrossRef]

18. Kallio, E. Integrative thinking is the key: An evaluation of current research into the development of adult thinking. Theor. Psychol. 2011, 21, 785-801. [CrossRef]

19. Alexander, C.; Langer, E. Introduction: Major issues in the exploration of adult growth. In Higher Stages of Human Development; Alexander, C., Langer, E., Eds.; Oxford University Press: New York, NY, USA, 1990; pp. 3-32.

20. Limon, M. The domain generality-specificity of epistemological beliefs: A theoretical problem, a methodological problem or both? Int. J. Educ. Res. 2006, 45, 7-27. [CrossRef]

21. Kallio, E.K. From multiperspective to contextual integrative thinking in adulthood. In Development of Adult Thinking: Interdisciplinary Perspectives on Cognitive Development and Adult Learning; Kallio, E.K., Ed.; Routledge: Abingdon, UK, 2020; pp. 9-32.

22. Richards, R.C.; Gastil, J. Deliberation. In International Encyclopedia of Political Communication; Mazzoleni, G., Ed.; John Wiley and Sons: Chichester, UK, 2016; pp. 275-288.

23. Fishkin, J.S.; Mainsbridge, J. The prospects and limits of deliberative democracy. Daedalus 2017, 146, 6-84. [CrossRef]

24. Eagan, J.L. Deliberative Democracy: Political Theory. Available online: https://www.britannica.com/topic/deliberativedemocracy (accessed on 26 December 2020).

25. Ozanne, J.; Corus, C.; Saatcioglu, B. The philosophy and methods of deliberative democracy: Implications for public policy and marketing. J. Public Policy Mark. 2009, 28, 29-40. [CrossRef]

26. Organisation for Economic Co-operation and Development (OECD). Innovative Citizen Participation and New Democratic Institutions: Catching the Deliberative Wave; OECD Publishing: Paris, France, 2020. Available online: https://www.oecd-ilibrary.org/ governance/innovative-citizen-participation-and-new-democratic-institutions_339306da-en (accessed on 26 December 2020).

27. Weymouth, R.; Hartz-Karp, J.; Marinova, D. Repairing political trust for practical sustainability. Sustainability $2020,12,7055$. [CrossRef]

28. Curato, N.; Dryzek, J.S.; Ercan, S.A.; Hendriks, C.M.; Niemeyer, S. Twelve key findings in deliberative democracy research. Daedalus 2017, 146, 28-38. [CrossRef]

29. MosaicLab. What Is Deliberative Engagement (Deliberative Democracy)? Available online: https://www.mosaiclab.com.au/ what-is-deliberative-democracy (accessed on 30 October 2020). 
30. Escobar, O.; Elstub, S. Forms of Mini-Publics. Available online: https://newdemocracy.com.au/wp-content/uploads/2017/05/ docs_researchnotes_2017_May_nDF_RN_20170508_FormsOfMiniPublics.pdf (accessed on 30 October 2020).

31. Scott, K. What Makes Deliberation Different from Other Forms of Consultation? 2018. Available online: https://www.involve. org.uk/resources/blog/opinion/what-makes-deliberation-different-other-forms-consultation (accessed on 26 November 2020).

32. Carson, L.; Hartz-Karp, J.; Briand, M. Deliberative democracy as a reform movement. In The Oxford Handbook of Deliberative Democracy; Bächtiger, A., Dryzek, J., Mansbridge, J., Warren, M., Eds.; Oxford University Press: Oxford, UK, 2018 ; pp. 697-709.

33. Carcasson, M. Effective Facilitation for Deliberation. 2014. Available online: https://cdn.naaee.org/sites/default/files/3. _effective_facilitation_for_deliberation.pdf (accessed on 27 November 2020).

34. Dias, N. Hope for Democracy: 30 Years of Participatory Budgeting Worldwide; Epopeia Records: Faro, Portugal, 2018; Available online: https:/ / www.oficina.org.pt/uploads/7/0/6/1/70619115/hope_for_democracy_-_digital.pdf (accessed on 30 October 2020).

35. Thompson, N. Participatory budgeting-The Australian way. J. Public Delib. 2012, 8, 5.

36. Christensen, H.; Grant, B. Participatory budgeting in Australian local government: An initial assessment and critical issues. Aust. J. Public Adm. 2016, 75, 457-475. [CrossRef]

37. Ebdon, C.; Franklin, A.L. Citizen participation in budgeting theory. Public Adm. Rev. 2006, 66, 437-447. [CrossRef]

38. Abati, Y.B. Random Election, the G1000 and Deliberation to Change Madrid. 2017. Available online: https:/ / www.opendemocracy. net/democraciaabierta/yago-bermejo-abati/random-election-g1000-and-deliberation-to-change-madrid (accessed on 31 October 2020).

39. Healthy Democracy. Citizens' Initiative Review. Available online: https://healthydemocracy.org/cir/ (accessed on 31 October 2020).

40. Involve. Oregon Citizens' Initiative Review. Available online: https://www.involve.org.uk/resources/case-studies/oregoncitizens-initiative-review (accessed on 31 October 2020).

41. Victorian Legislation. Local Government Act 2020; Authorised Version No. 005. Available online: https://content.legislation.vic. gov.au/sites / default/ files/2020-10/20-9aa005\%20authorised.pdf (accessed on 15 December 2020).

42. Curato, N.; Vrydagh, J.; Bächtiger, A. Democracy without shortcuts: Introduction to the Special Issue. J. Deliberative Democr. 2020, 16, 1-9. [CrossRef]

43. Rosenberg, S.W. Citizen competence and the psychology of deliberation. In Deliberative Democracy: Issues and Cases; Elstub, S., McLaverty, P., Eds.; Edinburgh University Press: Edinburgh, UK, 2014; pp. 98-117.

44. Dryzek, J.S. Democratization as deliberative capacity building. Comp. Polit. Stud. 2009, 42, 1379-1402. [CrossRef]

45. Black, L.W.; Burkhalter, S.; Gastil, J.; Stromer-Galley, J. Methods for analyzing and measuring group deliberation. In Sourcebook of Political Communication Research: Methods, Measures and Analytical Techniques; Holbert, R.L., Ed.; Routledge: New York, NY, USA, 2010; pp. 323-335.

46. Jennstål, J. Deliberation and complexity of thinking. Using the Integrative Complexity Scale to assess the deliberative quality of minipublics. Swiss Polit. Sci. Rev. 2019. [CrossRef]

47. Niemeyer, S.; Veri, F. How Can We Improve Deliberative Reason? A Meta-Analysis of Minipublic Deliberation. 2020. Available online: https:/ / www.governanceinstitute.edu.au/events / centre-for-deliberative-democracy-and-global-governance-seminar/ 680/how-can-we-improve-deliberative-reason-a-meta-analysis-of-minipublic-deliberation (accessed on 15 December 2020).

48. Niemeyer, S. Intersubjective Reasoning in Political Deliberation: A Theory and Method for Assessing Deliberative Transformation at Small and Large Scale; Working Papers Series; University of Canberra: Canberra, Australia, 2019. Available online: https: //www.governanceinstitute.edu.au/magma/media/upload/ckeditor/files/Intersubjective\%20Reasoning(4).pdf (accessed on 15 December 2020).

49. Suedfeld, P. The Scoring of Integrative Complexity as a Tool in Forecasting Adversary Intentions: Three Case Studies. 2010. Available online: https:/ / apps.dtic.mil/dtic/tr/fulltext/u2/a526439.pdf (accessed on 30 October 2020).

50. Suedfeld's Integrative Complexity Research. Available online: https://www2.psych.ubc.ca/ \{\}psuedfeld/CXY.html (accessed on 30 October 2020).

51. Integrative Complexity. Available online: http://psychology.iresearchnet.com/social-psychology/decision-making/integrativecomplexity / (accessed on 30 October 2020).

52. Caroll, J.; Bright, A. Integrative Complexity of Wildfire Management: Development of a Scale. In Proceedings of the 2006 Northeastern Recreation Research Symposium, Bolton Landing, NY, USA, 9-11 April 2006; pp. 574-582. Available online: https:/ / www.nrs.fs.fed.us/pubs/gtr/gtr_nrs-p-14/75-carroll-p-14.pdf (accessed on 30 October 2020).

53. Suedfeld, P.; Tetlock, P.E.; Streufert, S. Conceptual/integrative complexity. In Motivation and Personality: Handbook of Thematic Content Analysis; Smith, C.P., Atkinson, J.W., McClelland, D.C., Veroff, J., Eds.; Cambridge University Press: New York, NY, USA, 1992; pp. 393-400.

54. Yin, R.K. Case Study Research and Applications: Design and Methods, 6th ed.; Sage: Los Angeles, CA, USA, 2017.

55. George, A.L.; Bennett, A. Case Studies and Theory Development in the Social Sciences; MIT Press: Cambridge, MA, USA, 2005.

56. Crowe, S.; Cresswell, K.; Robertson, A.; Huby, G.; Avery, A.; Sheikh, A. The case study approach. BMC Med. Res. Methodol. 2011, 11, 100. [CrossRef]

57. Newman, P.; Kenworthy, J. Sustainability and Cities: Overcoming Automobile Dependence; Island Press: Washington, DC, USA, 1999

58. MacTiernan, A. Harmonising Divergent Voices: Sharing the Challenge of Decision-Making. Keynote address. In Proceedings of the Institute of Public Administration Australia, New South Wales State Conference, Canberra, Australia, 10 November 2004. 
59. Weymouth, R.; Hartz-Karp, J. Deliberative collaborative governance as a democratic reform to resolve wicked problems and improve trust. J. Econ. Soc. Policy 2015, 17, 1-34.

60. Pahl-Wostl, C. The implications of complexity for integrated resources management. Environ. Model. Softw. 2007, 22, 561-569. [CrossRef]

61. SAGE. Retrospective Study. Encyclopedia of Research Design. 2010. Available online: https://methods.sagepub.com/reference/ encyc-of-research-design/n390.xml (accessed on 27 November 2020).

62. Bowen, G.A. Document analysis as a qualitative research method. Qual. R J. 2009, 9, 27-40. [CrossRef]

63. McCall, R.; Burge, J. Untangling wicked problems. Artif. Int. Eng. Des. Anal. Manuf 2016, 30, 200-210. [CrossRef]

64. Christensen, K. Building Shared Understanding of Wicked Problems. 2009. Available online: http://www.cognexus.org/Rotmaninterview_SharedUnderstanding.pdf (accessed on 21 November 2020).

65. Hartz-Karp, J. A Case Study in Deliberative Democracy: Dialogue with the City. Available online: https://activedemocracy.net/ articles/dialogue-city.pdf (accessed on 30 November 2020).

66. Weymouth, R.; Hartz-Karp, J. Participation in planning and governance: Closing the gap between satisfaction and expectation. Sustain Earth 2019, 2, 5. [CrossRef]

67. City of Greater Geraldton. IBM's Smart Cities Challenge. Available online: https://www.cgg.wa.gov.au/Profiles/cgg/Assets/ ClientData/Documents / Council-Meetings / 64/CEO014---Attatchment-1--IBM-SMarter-Cities-Challenge-CGG-Report.pdf (accessed on 30 November 2020).

68. Hartz-Karp, J. A case study in deliberative democracy: Dialogue with the City. J. Public Delib. 2005, 1, 6. [CrossRef]

69. Chwalisz, C. Introduction: Deliberation and new forms of governance. In Innovative Citizen Participation and New Democratic Institutions: Catching the Deliberative Wave; OECD Publishing: Paris, France, 2020; pp. 19-32. Available online: https://www. oecd-ilibrary.org/governance/innovative-citizen-participation-and-new-democratic-institutions_339306da-en (accessed on 27 November 2020).

70. Fishkin, J.S. Democracy When the People Are Thinking: Revitalizing Our Politics through Public Deliberation; Oxford University Press: Oxford, UK, 2018.

71. Lafont, C. The democratic case for political uses of mini-publics. Daedalus 2017, 146, 85-105. [CrossRef]

72. Abdullah, N.; Rahman, F. The use of deliberative democracy in public policy making process. Public Policy Adm. Res. 2015, 5, 221-229. [CrossRef]

73. Dryzek, J.S. Deliberative Democracy and Beyond: Liberals, Critics, Contestations; Oxford University Press: Oxford, UK, 2000.

74. Chwalisz, C. Reimagining democratic institutions: Why and how to embed public deliberation. In Innovative Citizen Participation and New Democratic Institutions: Catching the Deliberative Wave; OECD Publishing: Paris, France, 2020; pp. 121-148. Available online: https:/ / www.oecd-ilibrary.org/governance/innovative-citizen-participation-and-new-democratic-institutions_3393 06da-en (accessed on 27 November 2020). 